\title{
ОПЫТ МАКАРЕНКО В ПРЕДУПРЕЖДЕНИИ ПРЕСТУПНОСТИ НЕСОВЕРШЕННОЛЕТНИХ
}

\author{
Мацкевич И. М.
}

Аннотация: Предупреждение преступности несовершеннолетних остаётся в числе важснйших задач в работе правоохранительной системы любой страны. К сожалению, впрочем, как и всё, что связано с преступностью, эта проблема не имеет простых решений. Более того, в современной действительности, как никогда остро встают проблемы молодёжного насилия, экстремизма, многообразного отклоняющегося поведения отрицательной направленности. Для России эти, а также многие другие проблемы, непосредственно возникающие из преступности несовершеннолетних и молодёжи, также являются актуальными. Применив общенаучные методы анализа и сравнения, проанализирована законодательная конструкиия состава хищения предметов, имеющих особую иенность, а также момент окончания данного преступления. В заключении не могу с горечью не сказать, что установленный в Харькове памятник знаменитому советскому педагогу 24 октября 2011 г. был разобран. Между прочим, этот памятник был возведён в 1968 г. на собственные средства рабочих завода ФЭД. Человек, которого считают достоянием мировой цивилизации, оказался не нужен тем, для кого он трудился. И только потому, что его взгляды не соответствует современному видению историков Харькова.

Ключевые слова: Предупреждение, преступность, несовершеннолетний, насилие, дегуманизация, опасность, правонарушение, поведение, Макаренко, педагог.

Предупреждение преступности несовершеннолетних остаётся в числе важнейших задач в работе правоохранительной системы любой страны. К сожалению, впрочем, как и всё, что связано с преступностью, эта проблема не имеет простых решений. Более того, в современной действительности, как никогда остро встают проблемы молодёжного насилия, экстремизма, многообразного отклоняющегося поведения отрицательной направленности. Для России эти, а также многие другие проблемы, непосредственно возникающие из преступности несовершеннолетних и молодёжи, также являются актуальными.
Преступность несовершеннолетних отличается динамичностью, высокой степенью активности подростков. Люди, вставшие на путь совершения преступлений в юном возрасте, трудно поддаются исправлению и перевоспитанию и, как правило, представляют собой резерв для взрослой преступности.[1]

Выделяются следующие признаки преступности несовершеннолетних: 1) значительная часть преступлений совершается в отношении членов семьи, родственников и знакомых; 2) потерпевшими также являются несовершеннолетние и принадлежат они, чаще всего, к бытовой микросреде преступника; 3) преступления совершаются в 
квартирах знакомых; 4) большая часть преступлений представляет собой, так называемую, уличную преступность, при этом преступления квалифицируются в основном как хулиганство; 5) после 22 часов совершается около половины преступлений несовершеннолетних; 6) преступления совершаются в группе; 7) в преступной группе несовершеннолетних присутствует взрослый наставник с криминальным опытом; 8) при совершении преступлений характерна дерзость и циничность; 9) противоправная деятельность носит длящийся характер; 10) неоправданная жестокость при совершении преступлений. Особенностями структуры преступности несовершеннолетних являются: 1) более узкий круг совершаемых преступлений; 2) меньшая доля тяжких преступлений (преобладают кражи, грабежи и хулиганство, относительно редки убийства, тяжкие телесные повреждения, разбои); 3) незначительна доля неосторожных преступлений.

В то же время несовершеннолетние осваивают новые преступления: захват заложников, похищение человека (в том числе для занятия проституцией), торговля наркотиками и оружием, преступления в сфере информационных технологий, насильственные преступления на национальной и религиозной розни.

Агрессивные действия совершаются из-за бравады и из-за отсутствия реальной возможности оценить опасность своих поступков для окружающих. С каждым годом нарастает процесс дегуманизации (брутализации) преступного мира, повышается уровень жестокости, в том числе, в межличностных отношений между несовершеннолетними преступниками.

В настоящее время криминальные группировки несовершеннолетних имеют в своем основании националистические мотивы объединения. Существуют даже писанные правила националиста, среди которых: нельзя распространять информацию, которая может быть использована против националистического движения; для националиста не обязательна «раса тела», важнее «раса души»; в отношении своих - нельзя ничего, в отношении чужих - можно всё.
Групповой характер преступности несовершеннолетних определяется психологическими особенностями поведения человека в группе. Совершая преступление в группе, несовершеннолетний правонарушитель в известной мере теряет присущие ему индивидуальные черты, его поведение определяется психическим комплексом, свойственным группе в целом. Один, даже самый отъявленный подросток-хулиган не представляет опасности для окружающих. Но стоит ему оказаться в среде единомышленников, у него возникает немотивированное проявление агрессии по малейшему поводу, а часто и вовсе без повода. В составе каждой такой группы есть слабые, трусливые подростки, которые проявляют наибольшую активность при совершении противоправных действий. Группа позволяет скрыть несовершеннолетним собственную слабость и повысить уровень самооценки.

В неофициальных группах действуют другие способы самоутверждения: 1) невыполнение основных социальных обязанностей; 2) невыполнение принятых в обществе стандартов поведения; 3) аморальное поведение; 4) правонарушение; 5) возможность удовлетворения потребностей в сферах, представляющих интерес для несовершеннолетних, которые не может в силу объективных причин удовлетворить официальная структура.

Особенности психики несовершеннолетних способствуют их антиобщественному поведению в результате: 1) искажённого представления о таких важнейших нравственных понятиях как смелость, трусость, дружба, предательство, героизм, мужество; 2) ошибок в оценки поведения знакомых, неумение оценить человека в совокупности всех его свойств и качеств; 3) предпочтения оценки по внешним проявлениям человека без учета его подлинных мотивов и целей; 4) эмоциональной неуравновешенности, неустойчивости, повышенной возбудимости, резкой смены настроений; 5) обострённого отношения к окружающему, ко всему новому и незнакомому; 6) повышенной физической активности, избытка сил и энергии; 7) стремление к 
самостоятельности и самоутверждению любой ценой; 8) неприятия непродуманных и неграмотных форм воспитательного воздействия; 9) внушаемости, излишней доверчивости, склонности к подражательству; 10) более чувствительного отношения к происходящим в обществе негативным процессам и социальной несправедливости, понимаемой иногда превратно.

Выделяются следующие типы потерпевших от преступлений несовершеннолетних, как взрослые, так и их сверстники: 1) случайные знакомые, из одной и той же микросреды; 2) случайные знакомые, из другой микросреды, находящиеся в состоянии алкогольного или наркотического опьянения; 3) родственники, создающие своим поведением ситуацию, провоцирующую на совершение преступления; 4) лица, входящие в группы с антиобщественной ориентацией; 5) лица из конкурирующих группировок несовершеннолетних.

Мотивами совершения преступлений несовершеннолетними являются следующие: 1) мотив близкий к взрослому; 2) промежуточный; 3) детский. В последнем случае, преступления совершаются из озорства, любопытства, желания утвердить себя в глазах сверстников.

Исходя из вышеизложенного, представляется любопытным оглянуться назад и посмотреть, как со схожими проблемами боролись чуть менее ста лет назад, когда, кстати, условия для их решений были ещё хуже, чем сегодня. Разумеется, наиболее интересным является опыт работы известного советского педагога, социального работника по исправлению и перевоспитанию трудных подростков, а также несовершеннолетних правонарушителей, Антона Семёновича Макаренко.

Мой опыт аудиторной работы подсказывает, что сегодня не всякий помнит о Макаренко, поэтому несколько слов о нём. Без изучения его биографии, невозможно понять систему его взглядов и подходов.

Антон Семёнович Макарено родился 1 апреля (13 марта) 1888 г. в городе Белополье Сумского уезда Харьковской губернии. Его родители были рабочими малярами в железнодорожных вагонных мастерских. Кроме него в семье была младшая сестра, которая умерла в детстве, а также младший родной брат Виталий, о котором будет сказано несколько подробнее ниже.

В 1897 г. Антон Макаренко поступил в начальное железнодорожное училище. В 1901 г. семья переехала в город Крюков. Сейчас это район города Кременчуга Полтавской области на Украине. В 1904 г. Макаренко окончил четырёхклассное училище, а в 1905 г. одногодичные педагогические курсы. В том же 1905 г. начал работать учителем в железнодорожном училище, которое совсем недавно сам окончил. Его природный педагогический дар был замечен, и в 1914 г. по настоянию своих коллег он поступил в Полтавский учительский институт, который с блеском окончил в 1917 г., получив золотую медаль. Характерно название его дипломной работы, которую он великолепно защитил, «Кризис современной педагогики».

Надо отметить, что за год до этого Макаренко был призван в армию (ведь шла Первая мировая война), но вскоре был демобилизован из-за очень слабого зрения.

Октябрьскую революцию 1917 г. Макаренко в целом принял спокойно. Скорее всего, он не являлся активным сторонником болышевиков, но и царский режим не считал для себя идеальной формой государственного устройства.

В 1917 г. он возглавил железнодорожную школу при Крюковских вагонных мастерских. Можно сказать, он вернулся к истокам, поскольку его сознательная жизнь начиналась, как было сказано выше, в вагонных мастерских. Видимо здесь его заметил Ф.Э. Дзержинский, который, как известно, помимо руководства ВЧК занимался ещё восстановлением железнодорожного сообщения на бескрайних просторах страны. Впрочем, это произошло не сразу.

В 1919 г. Макаренко перебрался в Полтаву. Шла Гражданская война. Побочным следствием этой войны стала массовая детская беспризорность. Согласно разным оценкам экспертов число беспризорников в конце Гражданской войны 
колебалось в пределах от 4,5 до 7 млн. человек. Почти $100 \%$ среди них - это были подростки разных возрастов. Самое печальное, что практически все они добывали себе еду, совершая правонарушения разной степени тяжести.

В Полтаве Макаренко создал одну из первых колоний для несовершеннолетних правонарушителей. В течение короткого времени колония стала необычайно популярной. Феноменальным достижением Макаренко стало то, что никто из вчерашних несовершеннолетних преступников, находясь в колонии, не совершал преступлений. Но самое удивительное было то, что они не совершали преступлений и после выхода из неё. Подавляющее большинство бывших воспитанников колонии самым активным образом включилось в строительство нового доселе невиданного общества всеобщего благоденствия и справедливости. Таким образом, хотя сам Макаренко не ставил во главу угла идеологические установки и, тем более, большевистские идеи, его педагогическая практика оказалась очень близка новой советской власти. Можно сказать, формы педагогической работы, особенно, что касается трудового воспитания, с которыми экспериментировал Макаренко, совпали с идеологическими подходами большевиков. Несколько утрируя, Макаренко, возможно сам того не особенно желая, занялся подготовкой кадров для новой власти.

В 1921 г. колонии было присвоено имя писателя М. Горького, практика для того времени весьма распространённая, ведь переименовались в честь революционеров целые города, не то, что колонии. В 1926 г. колония была переведена в Куряжский монастырь, расположенный недалеко от Харькова. Макаренко руководил этой колонией до 1927 г. В октябре 1927 г. Макаренко попросили возглавить колонию, которая называлась - детская трудовая коммуна имени Ф.Э. Дзержинского, расположенная в пригороде всё того же Харькова. Коммуна была больше других, в ней содержались беспризорники, замешанные нередко в тяжких преступлениях. Структура управления коммуны находилась в плачевном состоянии. В общем, для Макаренко наступил период тяжелого испытания его практической теории социальной реабилитации несовершеннолетних преступников. И надо сказать, Макаренко с блеском преодолел все трудности. Со стороны может даже показаться, что для него это не составило никакого труда.

В коммуне Макаренко наладил производство знаменитых на весь Советский Союз фотоаппаратов ФЭД (аббревиатура от начальных букв имени, отчества и фамилии Дзержинского). И эти фотоаппараты производились в течение долгого времени и имели репутацию высококачественной продукции.

На примере своих коммунаров Макаренко доказал всем свои давно вынашиваемые теоретические гипотезы по влиянию на процесс воспитания и перевоспитания человека, даже человека с социально запущенными отклонениями в поведении, коллективного труда. Надо сказать, что педагогическими опытами Макаренко активно интересовался М. Горький, и они в течение длительного времени состояли в плодотворной переписке.

1 июля 1935 г. Макаренко был переведён в НКВД Украинской ССР, в связи с чем он переехал в Киев. В Киеве он был назначен на должность помощника начальника отдела трудовых колоний. Сугубо аппаратная работа была, очевидно, ему не интересна, и в ноябре 1936 г. он попросился перейти на работу обратно в трудовую колонию. Его просьба была удовлетворена, и до марта 1937 г. Макаренко руководил педагогической частью трудовой колонии в Броварах недалеко от Киева.

Впрочем, зенит его педагогической практики к этому времени был пройден. Не совсем понятно от кого исходила инициатива отдаления Макаренко от практической деятельности. Скорее всего, не от него. В противном случае не было бы попыток его возвращения на работу в колонию. С другой стороны, Макаренко был знаменит, успешен, обласкан представителями власти, и вполне возможно осознавал, что больше того, что он сделал, он уже ничего лучше сделать не сможет. Наконец, не исключено, что ему 
просто посоветовали (может быть, его коллеги из НКВД, как они умеют это делать, тонко намекая, что это единственно разумный путь) заняться обобщением своего опыта, что он сделал, как всегда умело и оригинально.

В марте 1937 г. Макаренко перевели в Москву. Это было повышение с отстранением от какой-либо деятельности вообще. Ему ничего не оставалось делать, как начать систематизировать и теоретически анализировать то, что он сделал за последние 20 лет. Для этого Макаренко избрал совершенно неожиданную форму - форму литературного художественного произведения. Это были не мемуары, а именно художественная проза. И такая неожиданная форма подачи практического материала имела едва ли не больший успех, чем удачная работа по перевоспитанию несовершеннолетних преступников.

31 января 1939 г. Указом Президиума Верховного Совета СССР А.С. Макаренко был награждён орденом Трудового Красного Знамени. Вскоре после этого Макаренко подал заявление о вступлении в партию большевиков (ВКПб). Чем вызвана подача заявления, остаётся только гадать. Очевидно, что Макаренко, возможно и разделяя некоторые идеи и подходы большевиков, всё-таки не был их безусловным сторонником. Может быть, он надеялся на продолжении карьеры. Или может быть ему настоятельно это рекомендовали сделать, особенно учитывая, что в стране полным ходом шли чистки и репрессии.

Как бы то ни было 1 апреля 1939 г. Макаренко ехал на пригородном поезде в Подмосковье, когда на станции Голицыно ему неожиданно стало плохо. Вызванные врачи лишь только констатировали факт смерти.

А.С. Макаренко было ровно 41 год. Он умер в день своего рождения. Похоронен с государственными почестями на Новодевичьем кладбище в Москве.

Примечательно, что на судьбу А.С. Макаренко никаким образом не повлияла участь его родного брата Виталия, о котором говорилось в самом начале. Дело в том, что младший брат Виталий в отличие от старшего брата не только не принял ни в каком виде Октябрьскую революцию, но начал вести против большевиков самую настоящую войну. Он выступил против них в Гражданской войне на стороне белых.

Виталий воевал в Первую Мировую войну, получил офицерское звание поручика и был участником знаменитого Луцкого прорыва, получившего впоследствии название Брусиловского, по имени генерала, возглавлявшего операцию. Виталий Семёнович Макаренко во время войны и Первой и Гражданской войн имел и ранения и награды. Он прожил долгую жизнь, в отличие от брата, и умер в эмиграции во Франции в 1983 г., немного не дожив до начала перестройки и дебольшевизации Советского Союза.

Как так получилось, что Макаренко не расплатился за прегрешения брата перед советской властью, - загадка. Или может быть расплатился?

Виталий Семёнович Макаренко не только поддерживал педагогические разработки брата, но и принимал в них непосредственное участие. Во всяком случае, считается, что Виталию принадлежит идея ввести в педагогическую практику работы с трудными подростками элементы военной игры с соответствующей атрибутикой, включая военную форму, военную дисциплину и военный строгий распорядок дня. Не надо забывать, что первые беспризорные дети появились не после Октябрьской революции 1917 г., а во время Первой Мировой войны.

Надо сказать, что предпринимались несколько попыток обобщить и систематизировать теоретическое наследие А.С. Макаренко. Все они были неудачными. Одна из последних была осуществлена в ФРГ. Тогда Виталия Макаренко нашли германские и французские учёные Г. Хиллиг и 3. Вайц. Они уговорили Виталия написать мемуары о своём брате, что тот и сделал.

В 1968 г. в ФРГ была создана лаборатория по изучению наследия А.С. Макаренко. Лаборатория входила в исследовательский Центр сравнительной педагогики Марбургского университета. В течение 10 лет по крупицам собирались все труды Макаренко, включая его 
изданные произведения, но с восстановлением текста, исключённого цензорами. В результате вышло 7 томов. Но это не было полным собранием сочинений Макаренко. Тем не менее, из-за трудностей с получением оригинального материала из Советского Союза, в 1982 г. работа была прекращена.

Между прочим, в Германии и сегодня успешно работает Schule mit Ausgleichsklassen A.S. Makarenko ( Школа компенсационных классов имени А.С. Макаренко, г. Магдебург).

На мой взгляд, среди творческого и практического наследия А.С. Макаренко нам важны следующие положения.

1. Он практически применил новейшие педагогические технологии в перевоспитании несовершеннолетних правонарушителей. Почему-то упускается, что Макаренко был прекрасным теоретиком, и прежде чем начать практиковать он обобщил мировой опыт в педагогике.

2. Едва ли не первым формой обобщения опыта своей работы он сделал художественные произведения. Оригинальность такого подхода заключалось, в том числе, в том, что это не только позволило критически подойти к себе, но и преодолеть неизбежные цензурные барьеры. Также Макаренко невероятно популяризировал свои идеи.

3. Решающее значение в его работе имел личностный фактор. Это был личностный фактор в перевоспитании (к каждому несовершеннолетнему правонарушителю он подходил особенно) и личностный фактор в практическом применении (хочешь сделать хорошо, сделай сам).

4. Он глубоко и искренне погружался в практические проблемы несовершеннолетних правонарушителей.

5. Он ввёл стандартизацию поведения и при этом настаивал на человеческой индивидуальности.

6. Использовал элементы воинского воспитания. Я бы даже сказал, - спартанского воспитания.

7. Придумал приёмы воспитания младших воспитанников старшими. Своего рода «дедовщина» со знаком плюс. Можно сказать, что это - воспитание преемственности.
8. Постоянно занимался переоценкой ценностей воспитанников. Искал тайные ключики к каждому своему подопечному. Проще говоря, искал в каждом скрытый талант.

9. Эксплуатировал коллективную ответственность, прекрасно осознавая её достоинства и недостатки. Он, как никто другой, ни до, ни после него, не умел так точно использовать её слабые н сильные стороны. И в этом ему помогала только его природная интуиция и дар педагога.

10. Коллективизм - как основа воспитательного процесса. На этом хотел бы остановиться более подробно.

Мне представляется, что А.С. Макаренко очень точно угадал, как использовать групповой характер противоправного поведения несовершеннолетних правонарушителей в целях их исправления и перевоспитания. Он сумел им внушить, что коллективизм - это та же самая группа, целью которого является справедливость, понимаемая так, как им нравится, ответственность каждого за каждого, понимаемая так, как им хочется, благо каждого, понимаемое, как высшее достижение нахождения в коллективе.

А.С. Макаренко выделял следующие главные достоинства коллектива.

1. Коллектив, по его мнению, объединяет людей не только в общей цели и в общем труде, но и в общей организации этого труда. При этом общая цель - не случайное совпадение частных целей, а именно цель всего коллектива. Каждое действие отдельного участника, каждая его удача или неудача должны расцениваться, как удача или неудача на фоне общего дела. Такая педагогическая логика должна пропитывать буквально каждый школьный день, каждое движение коллектива.

2. Коллектив является частью советского общества, органически связанный со всеми другими коллективами. На коллективе лежит ответственность перед обществом и страной. Только через коллектив каждый его член входит в общество. В этом суть понятия советской дисциплины. Только через осознание интересов 
коллектива возможна гармония личных интересов, воспитание чувства долга и чести.

3. Достижение целей коллектива, общий труд, долг и честь коллектива, не могут стать игрой случайных капризов отдельных людей. Коллектив - есть социальный организм, он обладает органами управления и координирования. Опыт коллективной жизни есть не только опыт соседства с другими людьми, это очень сложный опыт целесообразных коллективных движений, среди которых самое видное место занимают принципы распоряжения, обсуждения, подчинения большинству, подчинения товарища товарищу, ответственности и согласованности.

4. Советский коллектив, как полагал Макаренко, стоит на принципиальной позиции мирового единства трудового человечества. Это не просто бытовое объединение людей, это часть боевого фронта человечества в эпоху мировой революции. Все предыдущие свойства коллектива не будут звучать, если в его жизни не будет жить пафос исторической борьбы, переживаемой нами.

К этим четырём макаренским пунктам я бы добавил пятый. Его суть выразил в одном из интервью знаменитый хоккейный тренер, основоположник советского и российского современного хоккея с шайбой А. Отчество Тарасов.

Когда Тарасов был в Канаде, к нему обратился известный канадский хоккеист Уэйн Гретци. На тот момент Гретцки был невероятно популярен у себя на родине, в том числе и потому, что он играл в отличие от большинства своих коллег в техничный, а не силовой хоккей. Такой хоккей сами канадцы называли - русским. Гретцки спросил у Тарасова, нравится ли ему тот хоккей, который он демонстрирует. Тарасов ответил утвердительно. Тогда Гретцки спросил, можно ли сказать, что он играет, как русские. Тарасов ответил утвердительно. Возьмёте ли вы меня в свою сборную, спросил Гретцки, предвкушает положительный ответ. Нет, ответил Тарасов и пояснил, увидев, недоумение на лице Гретцки. Дело в том, объяснял он, что прежде чем играть в моей сборной, надо пройти детский сад, стать пионером в школе, потом комсомольцем. И только после того, как Гретцки пропитается на- сквозь духом коллективизма, он получит шанс стать кандидатом в сборную команду Советского Союза.

Сегодня методы социального воспитания и перевоспитания Макаренко забыты. Конечно, это не случайно. Главный недостаток, как мне представляется, всей макаренской системы заключается в отсутствие школы. Колонии Макаренко были хороши, когда в них работал Макаренко.

В то же время, А.С. Макаренко и его уникальный опыт совершенно недооценены в России. При этом, что примечательно, он был недооценён и в Советском Союзе. Считаю совершенно несправедливым, что до сих пор произведения Макаренко не изданы в полном объёме (без купюр и цензурных сокращений) в нашей стране, и призываю немедленно начать исправление этой ситуации.

Значение А.С. Макаренко заключается в том, что он, вероятно впервые в мире, доказал возможность полного исправления несовершеннолетних преступников, и в этом его система социального воспитания уникальна, а потому - должна быть изучена и востребована, в современных условиях. Разумеется, востребование опыта Макаренко не означает его слепого копирования. Думается, что и сам Макаренко очень бы удивился, если бы его методы стали не критически применять спустя почти 100 лет после его уникальных успешных экспериментов.

ЮНЕСКО в 1988 г. приняло решение о признании всего четырёх педагогов в мировой истории, которые определили новый способ педагогического мышления. Это: Джон Дьюи, Георг Кершенштейнер, Мария Монтессори и Антон Семёнович Макаренко.

В заключении не могу с горечью не сказать, что установленный в Харькове памятник знаменитому советскому педагогу 24 октября 2011 г. был разобран. Между прочим, этот памятник был возведён в 1968 г. на собственные средства рабочих завода ФЭД. Человек, которого считают достоянием мировой цивилизации, оказался не нужен тем, для кого он трудился. И только потому, что его взгляды не соответствует современному видению историков Харькова. 


\section{Библиография:}

1. Чашников В.А. Антикоррупционное образование как средство противодействия коррупции в органах внутренних дел // Полицейская и следственная деятельность. - 2014. - 4. - С. 39 - 48.

\section{References (transliterated):}

1. Chashnikov V.A. Antikorruptsionnoe obrazovanie kak sredstvo protivodeistviya korruptsii v organakh vnutrennikh del // Politseiskaya i sledstvennaya deyatel'nost'. - 2014. - 4. - C. 39 - 48. 